\title{
The Impact of Blood Flow Rate and Duration of Dialysis Session on Nutritional Status in Hemodialysis Patients
}

\author{
Nur Samsu ${ }^{1}$, Fatmawati ${ }^{2}$, Aurora Permatasari ${ }^{2}$, Kartin $^{3}$ \& Wahyu Wulandari ${ }^{4}$ \\ ${ }^{1}$ Department of Internal Medicine, Division of Nephrology and Hypertension, Faculty of Medicine, Universitas \\ Brawijaya, Malang, Indonesia \\ ${ }^{2}$ Dialysis Unit of Wava Husada Hospital, Malang, Indonesia \\ ${ }^{3}$ Dialysis Unit of Panti Nirmala Hospital, Malang, Indonesia \\ ${ }^{4}$ Dialysis Unit of Saiful Anwar Hospital, Malang, Indonesia \\ Correspondence: Nur Samsu MD, Department of Internal Medicine, Division of Nephrology and Hypertension, \\ Faculty of Medicine Universitas Brawijaya - Dr. Saiful Anwar Hospital, Malang, Indonesia. Tel: \\ 62-341-301-4528. E-mail: nur_samsu.fk@ub.ac.id
}

Received: June 18, 2020 Accepted: September 1, 2020 Online Published: September 16, 2020

doi:10.5539/gjhs.v12n11p106 URL: https://doi.org/10.5539/gjhs.v12n11p106

\begin{abstract}
Background: Blood flow rate (BFR) and time of dialysis are important determinants of dialysis adequacy. This study aimed to determine the impact of higher BFR and longer dialysis time on nutritional status in chronic hemodialysis (HD) patients.

Methods: Real-world evidence (RWE) studies of $3 \mathrm{HD}$ units in different hospitals that differ in BFR and/or dialysis time. Group I, HD $5 \mathrm{hr}$ and BFR 200-250 mL/min; group II, HD $4 \mathrm{hr}$ and BFR 270-320 $\mathrm{mL} / \mathrm{min}$, and group III, HD $4 \mathrm{hr}$ and BFR 200-250 mL/min. All HD units use the same dialysate flow and dialysis frequency. Nutritional status was assessed using a 3-point scale Subjective Global Assessment.

Results: A total of 233 chronic HD patients were included, mean of age was $52 \pm 12.9$ years, $46.5 \%$ were male. There are $69.5 \%$ on SGA class A, $27.5 \%$ on SGA class B, and 3\% on SGA class C. The proportion of SGA class A in group II was highest compared to group II and III $(93.5 \%$ vs $79.0 \%$ vs $32.1 \%(p<0.05)$. There was no SGA class $\mathrm{C}$ in group II, whereas $2.4 \%$ in group I and $7.4 \%$ in group III. In group II there was lower interdialytic weight gain (IDWG) and less use of anti-hypertensive drugs compared to group III $(\mathrm{p}<0.05)$.

Conclusion: Our study showed that higher BFR and longer dialysis time are associated with better nutritional status in chronic HD patients. A higher BFR seems to have a more substantial impact compared to a longer dialysis time.
\end{abstract}

Keywords: blood flow rate, dialysis time, subjective global assessment, nutritional status

\section{Introduction}

Dialysis adequacy reflects the efficacy of hemodialysis (HD) treatment and correlates well with nutritional status (Nunes et al., 2008). The National Kidney Foundation Kidney Disease Quality Outcomes Initiative (NKF-KDOQI) identifies urea clearance as a primary measure of dialysis adequacy (KDOQI, 2015). The minimum acceptable target for urea clearance during HD is a single-pool Kt/V of 1.2 or percent reduction of urea (PRU) of $65 \%$ three times per week (Jindal et al., 2006). Many factors are associated with an increase in urea clearance and possibly dialysis adequacy, namely blood flow rate (BFR) (Borzou et al., 2009; Hassel, Van der Sande, Kooman, Tordoir, \& Leunissen, 2001), dialyzer KoA (Mandolfo, Malberti, Imbasciati, Cogliati, \& Gauly, 2003), dialysis time, dialysis frequency (Locatelli et al., 2005), dialysate flow (Hauk, Kuhlmann, Riegel, \& Kohler, 2000), and needle size (Mehta, Deabreu, McDougall, \& Goldstein, 2002).

Increasing duration of dialysis is a useful method for increasing $\mathrm{Kt} / \mathrm{V}$, but it is not always possible because of economic factors and intolerance of patient. Also, increasing the flow rate of the dialysate leads to increased diffusion of urea from blood to the dialysate, but the effect cannot be prolonged. Also, using a high-quality filter is not economical (Kim et al., 2004; Daugirdas, Blake, \& Ing, 2001). Related to economic problems, then to the lowand low middle-income countries, increasing BFR seems to be the most rational choice to achieve adequate 
dialysis in HD patients.

The NKF KDOQI 2015 guidelines note that a BFR $(\mathrm{Qb})$ of less than $300 \mathrm{~mL} / \mathrm{min}$ provides insufficient clearance. There are no guidelines regarding the optimum BFR that can increase urea clearance, but on the other hand, it does not have a detrimental impact on patients. It has been suggested that a faster BFR may contribute to fistula complications such as venous pseudoaneurysm (Radmili et al., 2002), and hemolysis (Twardowski, Haynie, \& Moore, 1999). Furthermore, research suggests that little difference in patient outcomes exists when dialysis clearance targets are exceeded (Eknoyan et al., 2002). On the other hand, another study showed that even in patients with low access flow, increasing dialyzer BFR leads to an increase in delivered $\mathrm{Kt} / \mathrm{V}$ regardless of vascular access flow rate (Hassel et al., 2001). Borzou et al. (2009), also showed that a faster BFR increases Kt/V. George et al., 2017 showed that both BFRs (Qb $320 \mathrm{~mL} / \mathrm{min}$ and $\mathrm{Qb} 380 \mathrm{~mL} / \mathrm{min}$ ) would meet KDOQI guidelines for minimally adequate HD dose. However, only the faster BFR met both the URR and Kt/V KDOQI target values of $\mathrm{Kt} / \mathrm{V} 1.4$ and URR 70\%; the slower BFR met only the URR target. There was a statistically significant correlation between $\mathrm{Qb}$ and both URR and $\mathrm{Kt} / \mathrm{V}$, i.e., URR and $\mathrm{Kt} / \mathrm{V}$ increase when $\mathrm{Qb}$ increases (George, Whitlum, \& Duncan, 2017).

The impact of using faster BFR on fistula health is still debatable. However, there is relevant evidence that using faster BFR is associated with increased urea clearance, so it is suspected that there is a more significant long-term clinical benefit for patients undergoing HD using faster BFR compared to the lower BFR. This study aimed to determine the effect of increasing BFR and longer duration of dialysis session on nutritional status in maintenance HD patients.

\section{Methods}

\subsection{Patients}

Participants were patients with end-stage kidney disease who underwent HD in 3 HD units in 3 hospitals using different BFRs and/or duration of dialysis. All patients gave written informed consent before inclusion. Inclusion criteria were patients who were willing to participate in the study. They are 18 years or more when they first underwent HD, the people who had a duration of HD therapy of at least three months, two dialysis sessions per week, absence of severe cardiovascular disease, had never moved to other HD units at least in the past three months and has no problems with vascular access (good vascular access). We included a total number of 233 patients after obtaining consent to participate in this study. Additionally, the local ethics committee approved the research protocol with IRB number 400/124/K.3/302/2020.

\subsection{Study Design}

This RWE studies involved independent variables of BFR $(\mathrm{Qb})$, measured in $\mathrm{mL} / \mathrm{min}$ and duration of dialysis, measured in hours, and dependent variables of 3-point Subjective Global Assessment (SGA). Participants who follow the inclusion criteria were divided into groups based on HD program they are in (real setting) under the policies of each HD unit in each hospital. Each HD unit is the same in terms of dialyzer membrane (Nipro ELISIO $^{\mathrm{TM}} 13 \mathrm{H}$ ), dialysate flow rate $(500 \mathrm{~mL} / \mathrm{min}$ ), needles (16-gauge), dialysis machine (Nipro Surdial 55 Plus, Nipro Medical (Hefei) Co., LTD-China), dialysate composition, dialysis frequency (twice weekly). Group I was patients who underwent HD with a duration of 5 hours and using BFR $200-250 \mathrm{~mL} / \mathrm{min}$, group II were patients who underwent HD with a duration of 4 hours and using BFR 270-320 $\mathrm{mL} / \mathrm{min}$, and group III were patients who underwent HD with a duration of 4 hours and using BFR 200-250 mL/min. Baseline demographic data, including age, sex, and causes of end-stage renal disease (ESRD) were recorded, as well as clinical data, including average weight gain, blood transfusion, use of anti-hypertensive drugs, use of EPO and complaints including itching, feeling tired and weak, for at least the last three months also recorded from the patient's history and medical record.

\section{$2.3 S G A$}

The nutritional status of the patients was measured at study visit with a 3-point scale SGA. Using a structured evaluation form, the two independent trained and experienced renal nursing scored the patients' history of weight change in the previous six months, dietary intake change, gastrointestinal symptoms (loss of appetite, nausea, vomiting, and diarrhea), changes in functional capacity, loss of subcutaneous fat mass, muscle wasting, and edema and ascites. The interobserver agreement (kappa coefficient) was 0.84 . After evaluation, patients were categorized into three distinct classes of nutritional status; well-nourished (SGA class A), mild to moderately malnourished (SGA class B), and severely malnourished (SGA class C) as described by Detsky et al., 1987 (Detsky et al., 1987).

\subsection{Statistical Analysis}

Data with continuous variables were presented as mean $\pm \mathrm{SD}$. Categorical variables were presented in percentage 
and determined by the Pearson chi-square test. Differences between continuous variable were determined by independent student t-test or Mann-Whitney test as appropriate for two independent variables and one-way ANOVA test, followed by post hoc test using the least significant difference (LSD) for more than two independent variables. All technical data processing results were analysed by computerization using Statistical Product and Service Solution software, IBM SPSS Statistics 20, with a significance level of $0.05(\alpha=0.05)$.

\section{Results}

\subsection{Patient Characteristics}

A total of $233 \mathrm{HD}$ patients were included in the present study. The mean age of patients was $52 \pm 12.9$ years, and $46.5 \%$ were male. Diabetes accounts for about $35.4 \%$ of the total causes of ESRD, while in group III the proportion of diabetes is significantly higher than the other groups. Duration of dialysis in group I was significantly longer than the other two groups, whereas the duration of dialysis was the shortest in group II, but not significantly different compared to group III. For vascular access, the majority in all groups used AV fistula (66.7\%) as HD access. For group III the proportion of vascular access with AV fistula was significantly lower compared to the other two groups ( $51.9 \%$ vs $79.1 \%$ vs $78.9 \%$ ), whereas the use of catheter as vascular access was the most frequent in group III compared to the other two groups ( $48.1 \%$ vs $13.9 \%$ vs $10.1 \%)$. The use of anti-hypertensive drugs was significantly higher in group III compared to the other two groups. The use of ESA was the lowest in group II, in contrast to blood transfusion requirement was significantly more frequent in group II compared to other groups. On the other hand, the proportion of ESA use was significantly the highest in group I compared to other groups, but the proportion of blood transfusion requirements was only significantly lower compared to group II. In contrast, when compared with group III, it was not significantly different. (Tables 1 and 2). The majority of patients in this study were well-nourished (the proportion of SGA class A was $69.5 \%$ ), while those with mild to moderate malnutrition or SGA class B was $27.5 \%$ and $3 \%$ were severely malnourished (SGA class C) (Table 3 and Table 4). There were no HD patients who were severely malnourished in group II, whereas in group I and group II the proportion of patients who were severely malnourished or SGA class C are $2.4 \%$ and $7.4 \%$, respectively.

\subsection{The Impact of Higher Blood Flow Rate (Qb) During Hemodialysis on SGA Class}

For HD sessions with different BFRs, but with dialysis duration both of which are 4 hours, the proportion of SGA class A was significantly higher in HD that using BFR $270-320 \mathrm{~mL} / \mathrm{min}$ compared with HD using BFR 200-250 $\mathrm{mL} / \mathrm{min}(93.5 \%$ vs $32.1 \%, \mathrm{p}<0.001)$. On the contrary, the proportion of SGA score B was significantly higher in HD using BFR 200-250 mL/min compared with HD using BFR $270-320 \mathrm{~mL} / \mathrm{min}(60.5 \%$ vs $6.5 \%$, p <0.001) (Figure 1). HDs that use higher BFRs found lower IDWGs and less need for anti-hypertensive therapy compared to HDs with lower BFRs (Table 2).

\subsection{The Impact of Longer Duration of HD Session During Hemodialysis on SGA Class}

For HD sessions with differences in dialysis duration, but the same in BFR, the proportion of SGA class A was significantly higher in HD with a duration of HD session 5 hours compared with the duration of HD session 4 hours $(79.0 \%$ vs $32.1 \%, \mathrm{p}<0.001)$. In contrast, the proportion of SGA class B was significantly higher in the duration of HD session 4 hours compared with the duration of HD session 5 hours $(60.5 \%$ vs $18.6 \%, p<0.001)$ (Figure 2). The need for antihypertensive therapy was significantly less in the duration of HD session 5 hours compared with the duration of HD session 4 hours, but there was no difference in IDWG (Table 2).

Table 1. Patient characteristics according to the therapy group

\begin{tabular}{lccccc}
\hline \multirow{2}{*}{ Characteristic } & The amount, & \multicolumn{3}{c}{ Group } & p-value \\
\cline { 3 - 5 } & $\mathrm{n}(\%)$ & $\mathrm{I}(\mathrm{n}=43)$ & $\mathrm{II}(\mathrm{n}=109)$ & $\mathrm{III}(\mathrm{n}=81)$ & \\
\hline Age $(\mathrm{yr})$ & $52 \pm 12.9$ & $56 \pm 14.8^{\mathrm{a}}$ & $51 \pm 11.5^{\mathrm{b}}$ & $52 \pm 13.3^{\mathrm{b}}$ & $\mathrm{p}<0.05^{* * *}$ \\
Male sex (n,\%) & $113(46.5 \%)$ & $26(60.5 \%)$ & $44(40.4 \%)$ & $43(53.1 \%)$ & $\mathrm{p}=0.07^{*}$ \\
Female sex (n,\%) & $120(53.5 \%)$ & $17(39.5 \%)$ & $65(59.6 \%)$ & $38(46.9 \%)$ & \\
$\begin{array}{l}\text { Duration of dialysis, mon } \\
\text { (range) }\end{array}$ & $33.79 \pm 24.9$ & $44.91 \pm 29.9$ & $29.21 \pm 24.2$ & $39.59 \pm 20.7$ & $\mathrm{p}<0.05^{* *}$ \\
\hline
\end{tabular}




\begin{tabular}{|c|c|c|c|c|c|}
\hline \multicolumn{5}{|l|}{ Access type $(\mathrm{n}, \%)$} & \multirow[b]{3}{*}{$\mathrm{p}<0.001^{*}$} \\
\hline AV fistula & $162(66.7 \%)$ & $34(79.1 \%)$ & $86(78.9 \%)$ & $42(51.9 \%)$ & \\
\hline Catheter & $56(23 \%)$ & $6(13.9 \%)$ & $11(10.1 \%)$ & $39(48.1 \%)$ & \\
\hline Other & $15(6.2 \%)$ & $3(7.0 \%)$ & $12(11.0 \%)$ & $0(0.0 \%)$ & \\
\hline Mean IDWG (kg) & $1.86 \pm 0.69(1-4)$ & $2.15 \pm 0.67^{\mathrm{a}}$ & $1.57 \pm 0.67^{\mathrm{b}}$ & $2.09 \pm 0.58^{\mathrm{a}}$ & $\mathrm{p}<0.05 * * *$ \\
\hline \multicolumn{6}{|c|}{ Cause of ESRD (n, \%) } \\
\hline Diabetes & $86(35.4 \%)$ & $14(32.6 \%)$ & $28(25.5 \%)$ & $44(54.3 \%)$ & \multirow{2}{*}{$\mathrm{P}=0.002 *$} \\
\hline Non-diabetes & $14760.5 \%)$ & $29(67.4 \%)$ & $81(74.3 \%)$ & $37(45.7 \%)$ & \\
\hline \multicolumn{6}{|c|}{$\begin{array}{l}\text { Using anti-hypertensive drug } \\
(\mathrm{n}, \%)\end{array}$} \\
\hline Yes & $132(54.3 \%)$ & $22(51.2 \%)$ & $53(48.6 \%)$ & $57(70.4 \%)$ & \multirow{2}{*}{$\mathrm{p}=0.004^{*}$} \\
\hline No & $101(45.7 \%)$ & $21(48.8 \%)$ & $56(51.4 \%)$ & $24(29.6 \%)$ & \\
\hline \multicolumn{6}{|l|}{ Using ESA (n,\%) } \\
\hline Yes & $93(38.3 \%)$ & $30(69.8 \%)$ & $30(27.5 \%)$ & $33(40.7 \%)$ & \multirow{2}{*}{$\mathrm{p}<0.001^{*}$} \\
\hline No & $140(61.7 \%)$ & $13(30.2)$ & $79(72.5 \%)$ & $48(59.3 \%)$ & \\
\hline \multicolumn{6}{|c|}{ Blood transfusion (n,\%) } \\
\hline Yes & $61(25.1 \%)$ & $8(18.6 \%)$ & $41(37.6 \%)$ & $12(14.8 \%)$ & \multirow{2}{*}{$\mathrm{p}<0.001^{*}$} \\
\hline No & $172(74.9 \%)$ & $3581.4 \%)$ & $68(62.4 \%)$ & $69(85.2 \%)$ & \\
\hline \multicolumn{6}{|l|}{ Complaint (n,\%) } \\
\hline Yes & $24(24 \%)$ & $9(20.9 \%)$ & $24(22 \%)$ & $23(28.4 \%)$ & \multirow{2}{*}{$\mathrm{p}=0.45^{*}$} \\
\hline No & $177(76 \%)$ & $34(79.1 \%)$ & $8578 \%)$ & $58(71.6 \%)$ & \\
\hline
\end{tabular}

Results are expressed as the mean $\pm S D$, number (\%), or range (minimum-maximum). ${ }^{*}$ Chi-square test; ** Mann-Whitney $\mathbf{U}$ test; ***one-way ANOVA test followed by least significant difference. $a$ and $b$ denote the difference annotations that imply significant differences $(p<0.05)$. Abbreviations: ESRD, end-stage renal disease; ESA, Erythropoiesis-stimulating agents, IDWG, Interdialytic weight gain; AV, arteriovenous.

Table 2. Comparison of patient characteristics based on differences in BFR and duration of dialysis sessions

\begin{tabular}{|c|c|c|c|c|c|c|}
\hline \multirow[b]{2}{*}{ Characteristic } & \multicolumn{3}{|c|}{ BFR $200-250 \mathrm{~mL} / \mathrm{min}$} & \multicolumn{3}{|c|}{ Dialysis time $4 \mathrm{hrs}$} \\
\hline & $\begin{array}{l}\text { Dialysis time } 5 \\
\text { hrs }(n=43)\end{array}$ & $\begin{array}{c}\text { Dialysis time } 4 \\
\text { hrs }(\mathrm{n}=81)\end{array}$ & $\mathrm{p}$ value & $\begin{array}{c}\text { BFR 270-320 } \\
\mathrm{mL} / \mathrm{min}(\mathrm{n}=109)\end{array}$ & $\begin{array}{l}\text { BFR 200-250 } \\
\mathrm{mL} / \mathrm{min}(\mathrm{n}=81)\end{array}$ & $\mathrm{p}$ value \\
\hline Age (yr) & $56 \pm 14.8$ & $52 \pm 13.3$ & $0.071 * *$ & $51 \pm 11.5$ & $52 \pm 13.3$ & $0.754 * *$ \\
\hline Male sex $(n, \%)$ & $26(60.5 \%)$ & $43(53.1 \%)$ & $0.276^{*}$ & $44(40.4 \%)$ & $43(53.1 \%)$ & $0.056^{*}$ \\
\hline Female sex $(\mathrm{n}, \%)$ & $17(39.5 \%)$ & $38(46.9 \%)$ & & $65(59.6 \%)$ & $38(46.9 \%)$ & \\
\hline $\begin{array}{l}\text { Duration of dialysis, } \\
\text { mon (range) }\end{array}$ & $\begin{array}{l}44.91 \pm 29.9 \\
(3-106)^{\mathrm{a}}\end{array}$ & $\begin{array}{l}39.59 \pm 20.7 \\
(3-78)^{b}\end{array}$ & $0.026 * *$ & $\begin{array}{l}29.21 \pm 24.2 \\
(4-135)^{\mathrm{b}}\end{array}$ & $\begin{array}{l}39.59 \pm 20.7 \\
(3-78)^{b}\end{array}$ & $0.109 * *$ \\
\hline \multicolumn{7}{|l|}{ Access type $(n, \%)$} \\
\hline AV fistula & $34(79.1 \%)$ & $42(51.9 \%)$ & & $86(78.9 \%)$ & $42(51.9 \%)$ & \\
\hline Catheter & $6(13.9 \%)$ & $39(48.1 \%)$ & $<0.001 *$ & $11(10.1 \%)$ & $39(48.1 \%)$ & $<0.001^{*}$ \\
\hline Other & $3(7.0 \%)$ & $0(0.0 \%)$ & & $12(11.0 \%)$ & $0(0.0 \%)$ & \\
\hline Mean IDWG (kg) & $2.15 \pm 0.67^{\mathrm{a}}$ & $2.09 \pm 0.58^{\mathrm{a}}$ & $0.654 * *$ & $1.57 \pm 0.67^{\mathrm{b}}$ & $2.09 \pm 0.58^{\mathrm{a}}$ & $<0.001 * *$ \\
\hline \multicolumn{7}{|l|}{ Cause of ESRD (n, \%) } \\
\hline Diabetes & $14(32.6 \%)$ & $44(54.3 \%)$ & \multirow{2}{*}{$0.016^{*}$} & $28(25.5 \%)$ & $44(54.3 \%)$ & \multirow{2}{*}{$<0.001 *$} \\
\hline Non-diabetes & $29(67.4 \%)$ & $37(45.7 \%)$ & & $81(74.3 \%)$ & $37(45.7 \%)$ & \\
\hline
\end{tabular}




\begin{tabular}{|c|c|c|c|c|c|c|}
\hline $\begin{array}{l}\text { Using } \\
\text { anti-hy } \\
(\mathrm{n}, \%)\end{array}$ & & & \multirow{3}{*}{$0.028^{*}$} & & & \multirow{3}{*}{$0.002 *$} \\
\hline \multirow{2}{*}{$\begin{array}{l}\text { Yes } \\
\text { No }\end{array}$} & \multirow{2}{*}{$\begin{array}{l}22(51.2 \%) \\
21(48.8 \%)\end{array}$} & \multirow{2}{*}{$\begin{array}{l}57(70.4 \%) \\
24(29.6 \%)\end{array}$} & & \multirow{2}{*}{$\begin{array}{l}53(48.6 \%) \\
56(51.4 \%)\end{array}$} & \multirow{2}{*}{$\begin{array}{l}57(70.4 \%) \\
24(29.6 \%)\end{array}$} & \\
\hline & & & & & & \\
\hline \multicolumn{7}{|c|}{ Using ESA (n,\%) } \\
\hline Yes & $30(69.8 \%)$ & $33(40.7 \%)$ & \multirow{2}{*}{$0.002 *$} & $30(27.5 \%)$ & $33(40.7 \%)$ & \multirow{2}{*}{$0.040^{*}$} \\
\hline No & $13(30.2)$ & $48(59.3 \%)$ & & $79(72.5 \%)$ & $48(59.3 \%)$ & \\
\hline \multicolumn{7}{|c|}{$\begin{array}{l}\text { Blood transfusion } \\
(\mathrm{n}, \%)\end{array}$} \\
\hline Yes & $8(18.6 \%)$ & $12(14.8 \%)$ & \multirow{2}{*}{$0.380 *$} & $41(37.6 \%)$ & $12(14.8 \%)$ & \multirow{2}{*}{$<0.001^{*}$} \\
\hline No & $3581.4 \%)$ & $69(85.2 \%)$ & & $68(62.4 \%)$ & $69(85.2 \%)$ & \\
\hline \multicolumn{7}{|c|}{ Complaint (n,\%) } \\
\hline Yes & $9(20.9 \%)$ & $23(28.4 \%)$ & \multirow{2}{*}{$0.248^{*}$} & $24(22 \%)$ & $23(28.4 \%)$ & \multirow{2}{*}{$0.201^{*}$} \\
\hline No & $34(79.1 \%)$ & $58(71.6 \%)$ & & $8578 \%)$ & $58(71.6 \%)$ & \\
\hline
\end{tabular}

Results are expressed as the mean $\pm S D$, number (\%), or range (minimum-maximum). a and $b$ denote the difference annotations that imply significant differences $(p<0.05)$. * Chi-square test; ** Independent student t-test Abbreviations: ESRD, end-stage renal disease; ESA, Erythropoiesis-stimulating agents, IDWG, Interdialytic weight gain; AV, arteriovenous.

Table 3. Comparison proportion of SGA class based on differences of dialysis session

\begin{tabular}{lccc}
\hline \multirow{2}{*}{ SGA class } & \multicolumn{3}{c}{ BFR 200-250 $\mathrm{mL} / \mathrm{min}$} \\
\cline { 2 - 4 } & Dialysis time 5 hrs (n=43) & Dialysis time 4 hrs (n=81) & $\mathrm{p}$ value* \\
\hline Class A & $34(79.0 \%)$ & $26(32.1 \%)$ & $\mathrm{p}<0.001$ \\
Class B & $8(18.6 \%)$ & $49(60.5 \%)$ & $\mathrm{p}<0.001$ \\
Class C & $1(2.4 \%)$ & $6(7.4 \%)$ & $\mathrm{P}=0.243$ \\
\hline
\end{tabular}

Results are expressed as number (\%). * Chi-square test. Abbreviations: BFR, blood flow rate, HD, hemodialysis, SGA, subjective global assessment.

Table 4. Comparison proportion of SGA class based on differences in BFR

\begin{tabular}{lccc}
\hline \multirow{2}{*}{ SGA class } & \multicolumn{3}{c}{ Dialysis time $4 \mathrm{hrs}$} \\
\cline { 2 - 4 } & BFR $270-320 \mathrm{~mL} / \mathrm{min}(\mathrm{n}=109)$ & BFR $200-250 \mathrm{~mL} / \mathrm{min}(\mathrm{n}=81)$ & $\mathrm{p}$ value* \\
\hline Class A & $102(93.5 \%)$ & $26(32.1 \%)$ & $\mathrm{p}<0.001$ \\
Class B & $7(6.5 \%)$ & $49(60.5 \%)$ & $\mathrm{p}<0.001$ \\
Class C & $0(0.0 \%)$ & $6(7.4 \%)$ & $\mathrm{P}=0.004$ \\
\hline
\end{tabular}

Results are expressed as number (\%). * Chi-square test. Abbreviations: BFR, blood flow rate, HD, hemodialysis, SGA, subjective global assessment. 


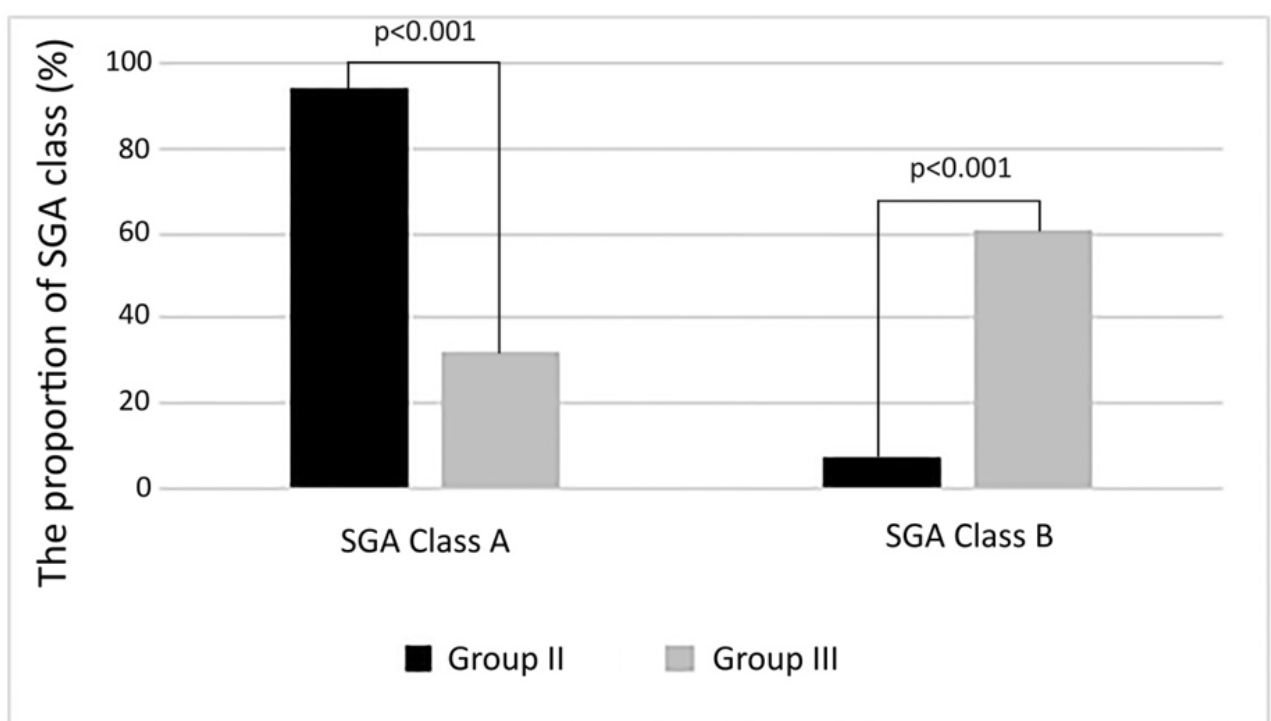

Figure 1. Histogram the proportion of SGA class A and B based on differences in BFR. Group II, BFR 270-320 $\mathrm{mL} / \mathrm{min}$; Group III, BFR 200-250 mL/min. The duration of dialysis for each group was the same, i.e. 4 hours. SGA, subjective global assessment

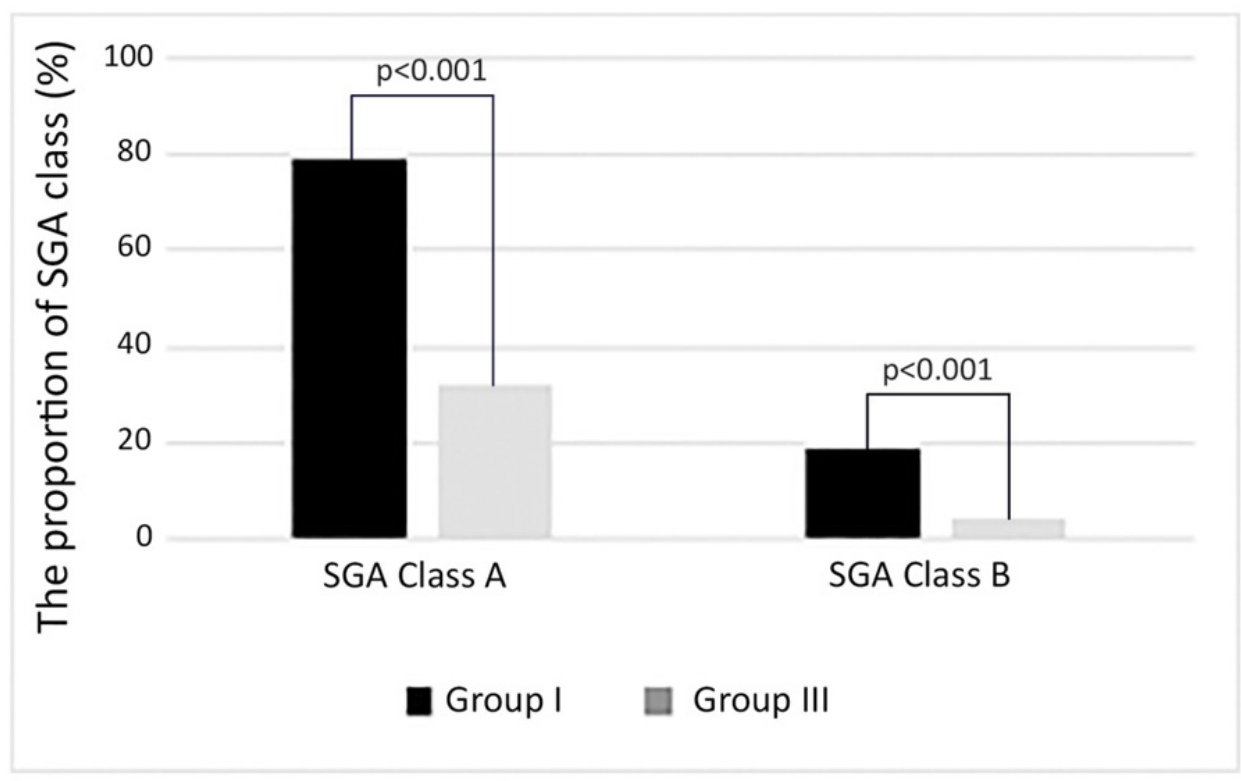

Figure 2. Histogram the proportion of SGA class A and B based on differences in duration of HD session. Group I, duration of HD session 5 hours, Group III, duration of HD session 4 hours. BFR for each group was the same, i.e. 200-250 $\mathrm{mL} / \mathrm{min}$. SGA, subjective global assessment

\section{Discussion}

Real-world evidence (RWE) studies aim to assess the impact of BFR and longer duration of HD session on nutritional status in maintenance HD patients. Nutritional status in this study was measured using the SGA questionnaire. The SGA is a tool which can rapidly assess the malnutrition score with a minimal technical requirement and had a high degree of interobserver agreement (Detsky et al., 1987). SGA was found in several studies to be a reliable tool for evaluating nutritional status (Steiber et al., 2007; Dai et al., 2017; Gupta, Srivastava, Narain, \& Saraswat, 2017) and associated with clinical characteristics, anthropometric and nutritional biomarkers (Steiber et al., 2007; Dai et al., 2017; De Mutsert et al., 2009). The NKF/DOQI,2000 recommended SGA as a nutrition assessment for the MHD population.

Our results show that the majority of our HD patients, based on SGA class are well-nourished (SGA class A was 
$69.5 \%$ ) while the rest $(27.5 \%$ ) had mild-to-moderate malnourished (SGA class B), and 3\% had severe malnourished (SGA class C). It is well known that an essential factor in achieving functional nutritional status in HD patients is adequate dialysis. The previous study has shown that the adequacy of dialysis reflects the efficacy of HD treatment and correlates well with nutritional status (Nunes et al., 2008; NKF-KDOQI, 2000). The results of many surveys show that achieving a Kt/V of 1.2 or more and URR of $65 \%$ or more is effective in improving the prognosis of patients on dialysis (Lindsay \& Spanner, 1997). Therefore, achieving this goal remains one aims of dialysis. Many factors can increase Kt/V and URR including use of high-level dialyzers, increasing blood flow rate (BFR), increasing the flow of dialysate and dialysis time; some of these methods cannot be used routinely due to economic constraints and poor patient compliance to prolong dialysis time (Hauk et al., 2000; Cigarran, Coronel, Torrente, \& Sevilla, 2004). Therefore for low income-countries, increasing BFR seems to be the most rational choice to achieve adequate dialysis in HD patients.

Blood flow rate (BFR) during HD is one of the important determinants of increasing dialysis dose (Chang, Kim, \& Kim, 2016). Hassel et al., (2001) reported that a 30\% increase in BFR, giving the same surface, membrane and dialysate flow, resulted in a $23 \%$ increase in urea clearance. Using BFR of $200 \mathrm{~mL} / \mathrm{min}, 16.7 \%$ of patients had $\mathrm{Kt} / \mathrm{V}$ higher than 1.3 and URR higher than 65 . On the other hand, with BFR of $250 \mathrm{~mL} / \mathrm{min}, 26.2 \%$ of patients had $\mathrm{Kt} / \mathrm{V}$ higher than 1.3 , and $35.7 \%$ of subjects had URR higher than 65 . These results confirm that increasing the BFR by $25 \%$ is effective in increasing dialysis adequacy in HD patients (Borzou et al., 2009). Another study suggests that increasing BFR by $15-20 \%$ of the previous flow rate is effective in achieving dialysis adequacy in HD patients with low Kt/V (Kim et al., 2004). Therefore, it may be postulated that lower BFR may cause inadequate dialysis and influence on clinical outcomes in HD patients (Chang et al., 2016). KDOQI (NKF-KDOQI, 2006) guidelines identify that a $\mathrm{BFR}(\mathrm{Qb})$ of less than $300 \mathrm{~mL} / \mathrm{min}$ does not provide sufficient clearance. There are no guidelines as to the optimal BFR greater than $300 \mathrm{~mL} / \mathrm{min}$. The DOPPS has shown that in the United States, the patients that BFR is more than $400 \mathrm{~mL} / \mathrm{min}$ account for $83.6 \%$ of the HD patients. In Canada and other Europe, the patients with BFR $\geq 250 \mathrm{~mL} / \mathrm{min}$ take about $98 \%$ of the HD patients. Nevertheless, attention should be given to factors such as patients' tolerance, hemodynamic status, using a suitable filter according to patients' weight (Borzou et al., 2009). Determining the impact of BFRs on urea clearance is essential for clinicians to enact evidence-informed practice and protect patients from harm. George et al., 2017 showed that both BFRs (Qb 320 $\mathrm{mL} / \mathrm{min}$ and $\mathrm{Qb} 380 \mathrm{~mL} / \mathrm{min}$ ) would meet KDOQI guidelines for minimally adequate $\mathrm{HD}$ dose (Kt/V 1.2 and URR $65 \%$ ). Interestingly, only the faster BFR met both the URR and Kt/V KDOQI target values of Kt/V 1.4 and URR $70 \%$; the slower BFR met only the URR target (DOPPS, 2015).

Our results show that BFR $270-320 \mathrm{ml} / \mathrm{min}$ with the same membrane, dialysate flow, dialysis time, and dialysis machine is associated with better nutritional status compared to BFR $200-250 \mathrm{ml} / \mathrm{min}$. Besides, using BFR of 270-320 ml/min, there were no severe malnourished patients, whereas $7.4 \%$ of HD patients with BFR of 200-250 $\mathrm{ml} / \mathrm{min}$ were SGA class C or severely malnourished (Table 4 and Figure 1). Unfortunately, in this study we did not evaluate urea clearance (Kt/V or URR), so the exact cause of better nutritional status in HD patients with BFR $270-320 \mathrm{ml} / \mathrm{min}$ cannot be ascertained. However, if we look at the results of several previous studies, this is most likely due to higher urea clearance with a higher BFR. Our data also showed that BFR of 270-320 $\mathrm{ml} / \mathrm{min}$ had lower interdialytic weight gain (IDWG) and significantly less need for anti-hypertensive drugs compared with BFR 200-250 $\mathrm{ml} / \mathrm{min}$ (Table 2). Overall, group II (BFR 270-320 $\mathrm{ml} / \mathrm{min}$ and 4 hours HD duration) obtained significantly smaller IDWG compared with group I $(1.57 \pm 0.67$ vs $2.15 \pm 0.67, \mathrm{p}<0.001)$ and group III $(1.57 \pm$ 0.67 vs $2.09 \pm 0.58, \mathrm{p}<0.001)$ and this is in line with the proportion of patients who were taking the anti-hypertensive drug which was significantly less in group II compared with group III (48, $6 \%$ vs $70.4 \%, p=$ 0.002). In contrast, when compared with group I, the difference was not significant ( $48.6 \%$ vs $51.2 \%, p>0.05)$ (Table 2). These results indicate that using a higher BFR is associated with lower IDWG and more controlled hypertension compared to using a lower BFR. The mechanism underlying these results is unclear but is likely related to higher urea clearance, which leads to better hypertension control. It is in line with Eknoyan et al., 2010 who reported that higher levels of urea clearance might be a marker for longer dialysis times, better control of blood pressure (BP) and extracellular fluid volume, or higher clearance of larger molecular weight substances.

Dialysis time is the most important as a factor influencing $\mathrm{Kt} / \mathrm{V}$, but prolong dialysis time is difficult to implement in practice because of its economic impact and poor patient compliance. Our results showed that HD with a duration of 5 hours, but with the same membrane, dialysate flow, blood flow rate, and dialysis machine is associated with better nutritional status compared to HD with a duration of 4 hours $(79.0 \%$ well-nourished on HD session 5 hours vs $60.5 \%$ mild-to-moderate malnourished on HD session 4 hours) (Figure 2). Also, severely malnourished was higher in 4-hour duration of HD compared to 5-hour HD (7.4\% vs 2.4\%, p <0.05) (Table 3 and Table 4). Our data also showed that in HD with a duration of 5 hours, the need for anti-hypertensive therapy was 
significantly less than 4 hours duration of HD, whereas there was no difference in IDWG (Table 2).

Outcome of diabetic patients on maintenance dialysis is worse than non-diabetics patients. These patients have nutritional markers of serum creatinine, and albumin was inferior to non-diabetics. In fact, diabetic patients are faced with malnutrition due to low protein intake and higher catabolic state (Soleymanian, Kokabeh, Mahjoub, Ramaghi, \& Argani, 2017). Unfortunately, in our study, the proportion of diabetes as a cause of ESRD was not the same between groups, where the proportion of diabetes was highest in group III significantly (Table 1). This might - in part - affect the patient's condition, which is reflected in the nutritional status in group III which is lower compared to other groups. However, when we see the difference in the proportion of SGA class A between groups I and II, which in group II with shorter HD duration, the proportion of SGA class A was higher than in group I. This evidence shows that with higher BFR in group II, which had a better impact on nutritional status compared to group III, not solely because of the higher proportion of diabetic patients in group III.

In terms of vascular access, there is a trend towards higher catheter utilization in diabetic patients (Soleymanian et al., 2017). Catheter use is accompanied by a lack of adequate dialysis and a higher risk of infection and inflammation, potentially affecting the survival of HD patients (Coentrao et al., 2015). In our study, the type of HD access was also not the same between groups. The group III's proportion of catheters was higher compared to other groups (Table 1). It might - in part - affect the nutritional status that can occur due to infection or inflammation. Same as the description above, that the lower proportion of SGA class A in group III was not solely due to the greater proportion of catheter access use, but because in group III using a lower BFR than group II.

\section{Conclusion}

In conclusion, our study showed that higher BFR and longer duration of HD sessions are associated with better nutritional status. A higher BFR seems to have a stronger influence on nutritional status compared to the longer duration of HD session. The results of this study also indicate that using a higher BFR is associated with lower IDWG and more controlled hypertension compared to using a lower BFR.

\subsection{Study Limitations}

This study has several limitations, related to the RWE study itself, including low internal validity, lack of quality control around data collection and vulnerability to various sources of bias for comparison results. The proportion of diabetes as the underlying ESRD and type of access are not the same between groups. We also did not measure urea clearance and other biochemical parameters related to nutritional status.

\section{Acknowledgments}

The authors would like to acknowledge and thank the participants and staff, including Fatmawati, Kartin, and Wahyu Wulandari for their involvement with and support of this study.

\section{Competing Interests Statement}

No potential conflict of interest relevant to this article was reported.

\section{References}

Arbor Research Collaborative for Health. DOPPS practice monitor [Internet]. Ann Arbor (MI): Arbor Research Collaborative for Health, c2015. Retrieved March 13, 2020, from https://www.dopps.org/DPM/Default.aspx

Borzou, S. R., Gholyaf, M., Zandiha, M., Amini, R., Goodarzi, M. T., \& Torkaman, B. (2009). The effect of increasing blood flow rate on dialysis adequacy in hemodialysis patients. Saudi J Kidney Dis Transpl, 20, 639-42. PMID: 19587507.

Chang, K. Y., Kim, S. H., \& Kim, Y. O. (2015). The impact of blood flow rate during hemodialysis on all-cause mortality. Korean J Intern Med, 31, 1131-1139. https://doi.org/10.3904/kjim.2015.111

Cigarran, S., Coronel, F., Torrente, J., \& Sevilla, M. (2004). Risk of inadequate dialysis dose in hemodialysis patients with high Watson volume: A Warning. Hemodial Int, $8,84$. https://doi.org/10.1111/j.1492-7535.2004.0085o.x

Coentrao, Luís, Van Biesen, W., Nistor, I., Tordoir, J., Gallieni, M., Marti Monros, A., \& Bolignano, D. (2015). Preferred haemodialysis vascular access for diabetic chronic kidney disease patients: a systematic literature review. Journal of Vascular Access, 16(4), 259-264. https://doi.org/10.5301/jva.5000323

Dai, L., Mukai, H., Lindholm, B., Olof Heimbürger, \& Qureshi, A. R. (2017). Clinical global assessment of nutritional status as predictor of mortality in chronic kidney disease patients. Plos One, 12(12), e0186659. https://doi.org/10.1371/journal.pone.0186659 
Daugirdas, J. T., Blake, P. G., \& Ing, T. S. (2001). Handbook of dialysis, little, brown and company boston (3rd ed.).

De Mutsert, R., Grootendorst, D. C., Boeschoten, E. W., Brandts, H., van Manen, J. G., Krediet, R. T., et al. (2008). Subjec-tive global assessment of nutritional status is strongly associated with mortality in chronic dialysis patients. Am J Clin Nutr., 89(3), 787-93. https://doi.org/10.3945/ajcn.2008.26970

Detsky, A. S., McLaughlin, J. R., Baker, J. P., Johnston, N., Whittaker, S., Mendelson, R. A., et al. (1987). What is subjective global assessment of nutritional status? JPEN J Parenter Enteral Nutr., 11(1), 8-13. https://doi.org/10.1177/014860718701100108

Eknoyan, G., Beck, G. J., Cheung, A. K., Daugirdas, J. T., Greene, T., Kusek, J. W., et al. (2002). Effect of dialysis dose and membrane flux in maintenance hemodialysis. $N$ Engl $J$ Med, 347, 2010-9. https://doi.org/10.1056/NEJMoa021583

George, K. S., Whitlum, L., \& Duncan, J. (2017). Examining the effect of blood flow rate on hemodialysis urea clearance. The CANNT Journal, 27(3).

Gupta, A., Srivastava, A., Narain, U., \& Saraswat, P. (2017). Subjective global assessment of the patients of chronic kidney disease undergoing dialysis. Int $J$ Adv Med., 4(2), 481-485. https://doi.org/10.18203/2349-3933.ijam20171046

Hassell, D. R. M., Sande, F. M. V. D., Kooman, J. P., Tordoir, J. P., \& Leunissen, K. M. L. (2001). Optimizing dialysis dose by increasing blood flow rate in patients with reduced vascular-access flow rate. American Journal of Kidney Diseases, 38(5), 948-955. https://doi.org/10.1053/ajkd.2001.28580

Hauk, M., Kuhlmann, M. K., Riegel, W., \& Hans, K. (2000). In vivo effects of dialysate flow rate on kt/v in maintenance hemodialysis patients. American Journal of Kidney Diseases, 35(1), 105-111. https://doi.org/10.1016/S0272-6386(00)70308-8

Jindal, K., Chan, C. T., Deziel, C., Hirsch, D., \& Culleton, B. F. (2006). Chapter 1: hemodialysis adequacy in adults. Journal of the American Society of Nephrology, $17(3$ suppl 1), S4-S7.

Kim, Y. O., Song, W. I., Yoon, S. A., et al. (2004). The effect of increasing blood flow rate on dialysis adequacy in hemodialysis patients with low Kt/v. Hemodial Int, $8(1), \quad 85$. https://doi.org/10.1111/j.1492-7535.2004.0085q.x

Lindsay, R. M., \& Spanner, E. (1997). Adequacy of hemo $\neg$ dialysis in the elderly. Geriatr Nephrol Urol, 7, 3.

Locatelli, F., Buoncristiani, U., Canaud, B., Kohler, H., Petitclerc, T., Zucchelli, P., et al. (2005). Dialysis dose and frequency. Nephrol Dial Transplant, 20, 285-96. https://doi.org/10.1093/ndt/gfh550

Mandolfo, S., Malberti, F., Imbasciati, E., Cogliati, P., \& Gauly, A. (2003). Impact of blood and dialysate flow and surface on performance of new polysulfone hemodialysis dialyzers. International Journal of Artificial Organs, 26(2), 113. https://doi.org/10.1177/039139880302600204

Mehta, H. K., Deabreu, D., McDougall, J. G., Goldstein, M. B. (2002). Correction of discrepancy between prescribed and actual blood flow rates in chronic hemodialysis patients with use of larger gauge needles. $\mathrm{Am}$ J Kidney Dis, 39, 1231-1235. https://doi.org/10.1053/ajkd.2002.33396

National Kidney Foundation. (2006). Updates: Clinical Practice Guidelines and Recommendations. Retrieved from https://www.kidney.org/sites/default/files/docs/12-500210_jag_dcp_guidelines-hd_oct06_sectiona_ ofc.pdf

National Kidney Foundation. (2000). Clinical practice guidelines for nutrition in chronic renal failure. K/DOQI. Am J Kidney Dis, 35, S1-140. https://doi.org/10.1053/ajkd.2001.20748

National Kidney Foundation. (2015). KDOQI Clinical Practice Guideline for Hemodialysis: 2015 Update. Retrieved from http://www.ajkd.org/article/S0272-6386(15)01019-7/pdf.

Nunes, F. T., Campos, G. D., Paula, S. M. X. D., Vânia, A. L. M., \& Oliveira, M. R. M. D. (2010). Dialysis adequacy and nutritional status of hemodialysis patients. Hemodialysis International, 12(1), 45-51. https://doi.org/10.1111/j.1542-4758.2008.00239.x

Radmili, O., Vasic, D., Vranes, M., Banzic, I., Cvetic, V., \& Davidovic, L. (2012). Venous pseudoaneurysm as a late complication of hemodialysis. American Surgeon. https://doi.org/10.1177/000313481207800511 
Soleymanian, T., Kokabeh, Z., Mahjoub, A., Ramaghi, R., \& Argani, H. (2017). Clinical outcomes and quality of life in hemodialysis diabetic patients versus non-diabetics. $J$ Nephropathol, 6(2), 81-89. https://doi.org/10.15171/jnp.2017.14

Steiber, A., Leon, J. B., Secker, D., McCarthy, M., McCann, L., Serra, M., ... \& Kalantar-Zadeh, K. (2007). Multicenter study of the validity and reliability of subjective global assessment in the hemodialysis population. Journal of Renal Nutrition, 17(5), 336-342. https://doi.org/10.1053/j.jrn.2007.05.004

Twardowski, Z. J., Haynie, J. D., \& Moore, H. L. (1999). Blood flow, negative pressure, and hemolysis during hemodialysis. Home Hemodialysis International, 3(1), 45-50. https://doi.org/10.1111/hdi.1999.3.1.45

\section{Copyrights}

Copyright for this article is retained by the author(s), with first publication rights granted to the journal.

This is an open-access article distributed under the terms and conditions of the Creative Commons Attribution license (http://creativecommons.org/licenses/by/4.0/). 